Article

\title{
Comparative Investigations on Different $\beta$-Glucosidase Surrogate Substrates
}

\author{
Felix Marcel Rainer Graf ${ }^{1,2}$ and Markus Buchhaupt 1,*(D) \\ 1 DECHEMA-Forschungsinstitut, Microbial Biotechnology, Theodor-Heuss-Allee 25, \\ 60486 Frankfurt am Main, Germany; felix.graf@dechema.de \\ 2 Faculty Biology and Chemistry, Justus-Liebig-Universität Gießen, Ludwigstraße 23, 35390 Gießen, Germany \\ * Correspondence: markus.buchhaupt@dechema.de
}

Citation: Graf, F.M.R.; Buchhaupt, M. Comparative Investigations on

Different $\beta$-Glucosidase Surrogate

Substrates. Fermentation 2022, 8, 83.

https://doi.org/10.3390/

fermentation 8020083

Academic Editor: Niel van Wyk

Received: 17 January 2022

Accepted: 14 February 2022

Published: 16 February 2022

Publisher's Note: MDPI stays neutral with regard to jurisdictional claims in published maps and institutional affiliations.

Copyright: (C) 2022 by the authors. Licensee MDPI, Basel, Switzerland. This article is an open access article distributed under the terms and conditions of the Creative Commons Attribution (CC BY) license (https:// creativecommons.org/licenses/by/ $4.0 /)$.

\begin{abstract}
: $\beta$-glucosidases are hydrolyzing enzymes which can release many aroma-active compounds from their glycoside form. Several yeasts produce these enzymes and thus are applied during the wine production process. To be able to test specific organisms for the presence of $\beta$-glucosidases and to investigate this enzyme activity, four main surrogate substrates have been described. The properties and applicability of these compounds, named arbutin (hydroquinone- $\beta$-D-glucopyranoside), esculin (6-O-(-D-glucosyl)aesculetin), 4-nitrophenyl- $\beta$-D-glucopyranoside (pNPG) and 4-methylumbelliferyl$\beta$-D-glucopyranoside (4-MUG), are discussed after comparing their advantages and disadvantages. Although all four substrates were found suitable for photometric assays, 4-MUG has proven to be most appropriate due to high sensitivity, high robustness and simple processing. Furthermore, the investigation of $\beta$-glucosidase product accumulation is described, which could be used to give indications about $\beta$-glucosidase localization.
\end{abstract}

Keywords: $\beta$-glucosidase; surrogate substrate; 4-MUG; screening; quantification

\section{Introduction}

A high proportion of the aromatic substances that are responsible for the flavor and taste of fruits occur as glycosides and thus do not contribute to the aroma profile [1]. Studies with grape juices or vine grapes showed that aroma glycoside concentrations are two to ten times higher than the concentrations of the free aromatic molecules [2,3]. The presence of aroma glycosides is also confirmed for many other industrially processed fruits like apricot, peach, yellow plum, quince, sour cherry, passion fruit, kiwi, papaya, pineapple, mango, lulo, raspberry and strawberry [3]. The most probable reason for the frequent binding of aromatic substances to several glucose molecules or other sugars is lower toxicity and better solubility of the glycosides, which is associated with a better storage capability $[4,5]$.

For the industrial processing of fruits, glycosides represent a great opportunity to enhance the aroma intensity of the products. A natural possibility to release aroma compounds from the glycosylated forms is the application of $\beta$-glucosidases, which are present in many non-Saccharomyces yeasts such as Aureobasidium pullulas [6-8] and Issatchenkia terricola [9]. Moreover, $\beta$-glucosidases are not only interesting with regard to the release of aroma-active substances, but for example also play an important role in the degradation of lignocellulosic biomass through the enzymatic route $[10,11]$.

In this study, four $\beta$-glucosidase surrogate substrates are compared and characterized with regard to their practical application possibilities. Since the first description of 4 -nitrophenyl- $\beta$-D-glucopyranoside (pNPG) for the assessment of $\beta$-glucosidase activities [12], this substrate has been widely used for the kinetic characterization of enzymes. Arbutin (hydroquinone- $\beta$-D-glucopyranoside) was used previously as a surrogate substrate for the screening of $\beta$-glucosidase activities in yeasts of oenological origin [13]. 6-O-(-D-Glucosyl)aesculetin (esculin) has traditionally been used to identify bacteria [14], 
and has recently been used in an esculin-glycerol solid medium for rapid screening of larger collections of native wine yeast strains [15]. Beside the frequent use of 4-methylumbelliferyl$\beta$-D-glucopyranoside (4-MUG) in the context of human $\beta$-glucosidase research $[16,17]$, the use of agar plates containing this surrogate substrate for microbiological screening purposes was described [18]. In 2005, a modified fast 4-MUG-based assay method in microplates with the possibility of $\beta$-glucosidase activity quantification was developed [19].

The structures of the aforementioned compounds are very similar (Figure 1). Hydrolysis of the $\beta$-glycosidic bond can be photometrically detected due to the absorption or fluorescence properties of either the glycoside or the aglycon forms.<smiles>Cc1cc(=O)oc2cc(O[C@@H]3O[C@H](CO)[C@@H](O)[C@H](O)[C@H]3O)ccc12</smiles><smiles>[B]C[C@H]1O[C@H](Oc2cc3ccc(=O)oc3cc2O)[C@H](O)[C@H](O)[C@H]1O</smiles><smiles>CC[C@H]1O[C@H](Oc2ccc([N+](=O)[O-])cc2)[C@H](O)[C@H](O)[C@H]1O</smiles><smiles>OC[C@H]1O[C@@H](Oc2ccc(O)cc2)[C@H](O)[C@@H](O)[C@H]1O</smiles>

Figure 1. Most common surrogate substrates for the detection of $\beta$-glucosidase activities. (A) 4-MUG, (B) Esculin, (C) pNPG, (D) Arbutin.

However, these surrogate substrates differ in their spectroscopic properties and in their application possibilities for $\beta$-glucosidase screening. A direct comparison of these substances is not yet available but will be helpful for the selection of the most suitable compound for screening approaches or other applications.

\section{Materials and Methods}

\subsection{Agar Plate Assays}

If not otherwise stated, all chemicals and enzymes were purchased from Sigma Aldrich (St. Louis, MO, USA). For esculin agar plates, $0.3 \mathrm{~g} \mathrm{~L}^{-1}$ ferric chloride, $1 \mathrm{~g} \mathrm{~L}^{-1}$ casein hydrolysate, $25 \mathrm{~g} \mathrm{~L}^{-1}$ yeast extract, $8 \mathrm{~mL} \mathrm{~L}^{-1}$ glycerol, $20 \mathrm{~g} \mathrm{~L}^{-1}$ agar and $1 \mathrm{~g} \mathrm{~L}^{-1}$ esculin were autoclaved and poured into petri dishes [15]. For arbutin plates, an equal amount of arbutin instead of esculin was used (respective data is not shown in the manuscript). For liquid assays with arbutin or esculin, the medium was prepared without agar. After incubation of the commercially available yeasts at $30^{\circ} \mathrm{C}$ for $48 \mathrm{~h}$, the formation of brown colorations was examined.

\subsection{Photometric Measurements}

A multimode microplate reader (Tecan Spark, Tecan AG, Männedorf, Switzerland) was used for photometric measurements. The below mentioned wavelengths for the measurements were previously identified for each surrogate substrate by performing excitation and emission scans between 300 and $600 \mathrm{~nm}$ of $100 \mu \mathrm{L}$ samples with $5 \mathrm{mM}$ surrogate concentration in $100 \mathrm{mM}$ citrate-phosphate buffer $\mathrm{pH}$ 7. The absorption of $p$-nitrophenol (pNP) was measured at $400 \mathrm{~nm}$. Fluorescence emission of 4-Methylumbelliferone (4-MU) was measured at $450 \mathrm{~nm}$ after excitation at $330 \mathrm{~nm}$, whereas fluorescence emission of esculin was measured at $454 \mathrm{~nm}$ after excitation at $367 \mathrm{~nm}$. Fluorescence measurements of arbutin took place at $325 \mathrm{~nm}$ after excitation at $260 \mathrm{~nm}$. For the assay with $\mathrm{pNP}$, transparent microplates were used. Arbutin, esculin and 4-MU were analyzed in black microplates. The amplification of the fluorescence signal after the transformation from light into electricity (Gain) was set to 60 AU for all fluorescence measurements. 


\section{3. $\beta$-Glucosidase Substrate Hydrolysis in Solution}

Enzyme kinetics were measured in $100 \mathrm{mM}$ citrate-phosphate buffer $\mathrm{pH} 7$ at room temperature after the addition of $10 \mu \mathrm{L}$ of a $2.5 \mathrm{U} \mathrm{mL}^{-1}$ solution of $\beta$-glucosidase from almonds (Sigma Aldrich) to the samples. Arbutin, esculin or 4-MUG were added using $100 \mu \mathrm{L}$ of a $5 \mathrm{mmol} \mathrm{L}^{-1}$ solution. Fluorescence spectra were measured in the same samples following the kinetic measurements. Accordingly, $50 \mu \mathrm{L}$ of a $10 \mathrm{mmol} \mathrm{L}^{-1}$ solution of pNPG were used for the experiments. Before measurement, $50 \mu \mathrm{L}$ of $0.1 \mathrm{~mol} \mathrm{~L}^{-1} \mathrm{Na}_{2} \mathrm{CO}_{3}$ were added to the sample. The absorption spectra of pNP were determined $20 \mathrm{~min}$ after enzyme addition. The total assay volume was $110 \mu \mathrm{L}$.

\subsection{Comparison of Assay Sensitivity and Linearity}

Fifty microliters of a $10 \mathrm{mmol} \mathrm{L}^{-1} 4$-MUG or pNPG solution in $100 \mathrm{mM}$ citratephosphate buffer $\mathrm{pH} 7$ were used and the assay was started by the addition of $10 \mu \mathrm{L}$ of different almond $\beta$-glucosidase sample dilutions. Afterwards, the increase in absorption or fluorescence was measured for five minutes. Samples of pNPG were mixed with $40 \mu \mathrm{L}$ of a $0.1 \mathrm{~mol} \mathrm{~L}^{-1} \mathrm{Na}_{2} \mathrm{CO}_{3}$ solution, samples of 4-MUG with $40 \mu \mathrm{L} \mathrm{H}_{2} \mathrm{O}$ before measurement. The signal emission slope per minute was calculated based on the measured values. For the pNPG assays we used enzyme amounts which resulted in constant slopes over an assay time of five minutes.

\subsection{Determination of $\mathrm{pH}$ Robustness of 4-MU Quantification}

Fluorescence spectra were measured in $50 \mu \mathrm{L}$ of a $10 \mathrm{mmol} \mathrm{L}^{-1} 4-\mathrm{MU}$ solution which was combined with $50 \mu \mathrm{L}$ of a $100 \mathrm{mM}$ citrate-phosphate buffer of the mentioned $\mathrm{pH}$ value. For the estimation of glucose and ethanol influences, the applied buffer was supplemented with the respective component. The total volume of the reaction mixture was $100 \mu \mathrm{L}$.

\subsection{Fluorescence Microscopy}

Prior to imaging, $50 \mu \mathrm{L}$ of cultures of Aureobasidium pullulans (CBS 100280) and Issatchenkia terricola (originated from the strain collection of the Hochschule Geisenheim University) were combined with $50 \mu \mathrm{L}$ of a $0.76 \mathrm{mmol} \mathrm{L}^{-1} 4$-MUG solution [19] in $100 \mathrm{mM}$ citrate-phosphate buffer $\mathrm{pH}$ 5.6. The used cultures were cultivated for $48 \mathrm{~h}$ at $30^{\circ} \mathrm{C}$ in deepwell plates containing $600 \mu \mathrm{L}$ Yeast Extract-Peptone-Dextrose Medium. After $10 \mathrm{~min}$ incubation at room temperature, images were acquired with an Axio Imager Z1 m fluorescence microscope (Carl Zeiss AG, Oberkochen, Germany) using a DAPI filter. The exposure time was set to $15 \mathrm{~s}$.

\section{Results}

\subsection{Necessity of Photometric Assays for Reliable $\beta$-Glucosidase Activity Determination}

Arbutin and esculin were often used in the context of agar plates to which iron compounds like ferric ammonium citrate [20] or ferric chloride [15] are simultaneously added. The complexation of iron by the released aglycons leads to the visible formation of elemental iron which indicates $\beta$-glucosidase activity. Initial tests with both compounds showed their suitability for respective assays in liquid culture. However, the outcome of respective tests with yeast suspension cultures of several commercially available wine yeasts was clearly different to the corresponding agar plate assay result in many cases (Figure 2). Only two of the commercial wine yeast strains caused a dark staining in the agar plate assay and in the liquid culture assay with esculin Kitzinger Aromatic was able to improve flavor diversity during fermentation, while Bioferm Malic improved the degradation of malic acid. One strain (Bioferm Rouge) caused no staining in both assays, but the other eight strains led to contrary results. Whereas the Kitzinger strains Champagner, Portwein, Universal, Bordeaux and Steinberg showed positive signals only in the liquid assays, the Bioferm strains Blanc, Doux and Killer caused iron complexation only in the agar plate assays. 


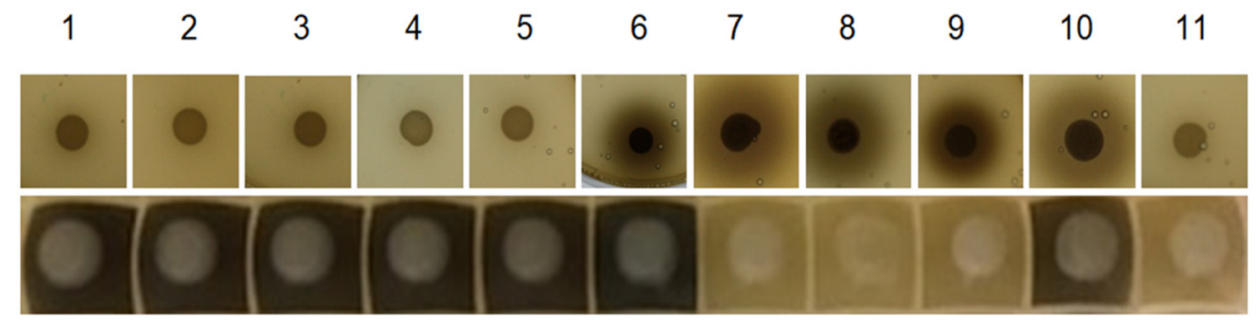

Figure 2. Comparison of esculin-based $\beta$-glucosidase activity detection on agar plates and in liquid culture. The $\beta$-glycosidic activity of commercial wine yeasts was detected by the occurrence of dark staining after cultivation on esculin-agar plates (top row) and in liquid esculin-containing media (bottom row). Details are described in the material and methods section. 1: Kitzinger Champagner, 2: Kitzinger Portwein, 3: Kitzinger Universal, 4: Kitzinger Bordeaux, 5: Kitzinger Steinberg, 6: Kitzinger Aromatic, 7: Bioferm Blanc, 8: Bioferm Doux, 9: Bioferm Killer, 10: Bioferm Malic, 11: Bioferm Rouge.

The described differences between yeast suspension cultures and agar plate assays confirm the necessity to adapt the assay conditions to the subsequent application in liquid conditions. Photometric measurements of liquid assays additionally enable precise activity quantification and are feasible in a high-throughput format using 96-well plates.

Because previous experiments revealed the possibility of direct fluorescence measurement of arbutin and esculin (data not shown), these compounds were measured in the following experiments without iron addition.

\subsection{Comparison of the Surrogate Substrates for Photometric Assays}

After investigation of the absorption or fluorescence properties of all compounds in form of the glycoside or the aglycon in scanning experiments (Figure S1), their hydrolysis was followed photometrically in experiments with $100 \mu \mathrm{L}$ of a $5 \mathrm{mmol} \mathrm{L}^{-1}$ glycoside solution to which almond $\beta$-glucosidase was added to a final concentration of $0.23 \mathrm{U} \mathrm{mL}^{-1}$ (Figure 3). The corresponding fluorescence emission and absorption spectra are presented in Figure S1.

Investigation of the arbutin solution showed fluorescence signals with an emission maximum at $325 \mathrm{~nm}$ under the selected conditions (Figure 3A). After the addition of almond $\beta$-glucosidase, the signal intensity slowly decreased within $12 \mathrm{~h}$ of measurement. Esculin showed higher fluorescence signals with an emission maximum at $455 \mathrm{~nm}$, which rapidly decreased over $5 \mathrm{~min}$ after the addition of $\beta$-glucosidase (Figure 3B). Although these two surrogate substrates were mainly used for agar plate applications during screening procedures, they can also be used to quantify $\beta$-glucosidase activities with fluorescence measurements in solutions, which has been recently stated also by two other studies [21,22]. In comparison, $\beta$-glucosidase-catalyzed pNPG hydrolysis led to increasing absorption values with a maximum at $400 \mathrm{~nm}$ (Figure 3C). 4-MUG hydrolysis led to increasing fluorescence signals at $450 \mathrm{~nm}$ up to 50,000 units within $10 \mathrm{~min}$ after addition of the enzyme (Figure 3D).

Hydrolysis of arbutin, esculin, pNPG or 4-MUG by an almond $\beta$-glucosidase clearly resulted in changes of the detectable photometric signals. While the detected compounds of 4-MUG and pNPG derive from products of the enzymatic reaction (4-MU and pNP), the hydrolysis of arbutin and esculin can be followed photometrically via the reduction of the substrate's fluorescence. Although the detection of fluorescence intensity decrease during $\beta$-glucosidase-mediated esculin hydrolysis represents a suitable assay, the detection of increasing absorption or fluorescence signal intensities during conversion of pNPG or 4-MUG is less error-prone. This is due to the fact that many parameters can lead to decrease of absorption or fluorescence signals, e.g., precipitation phenomena or $\mathrm{pH}$ changes, whereas an increase of signal intensity is rarely caused by artifacts. 


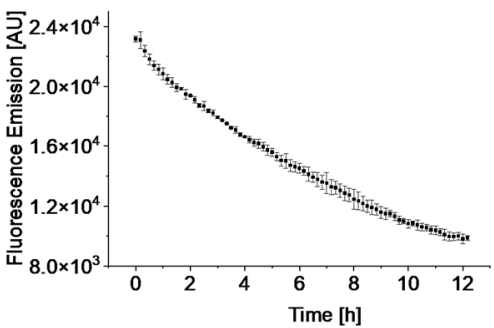

C

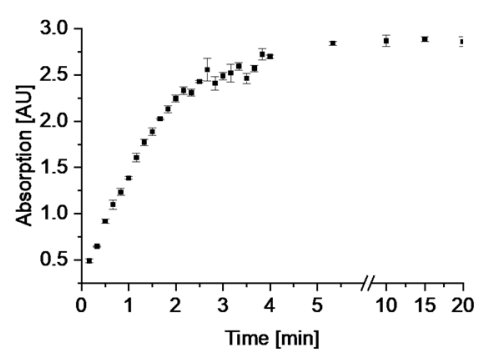

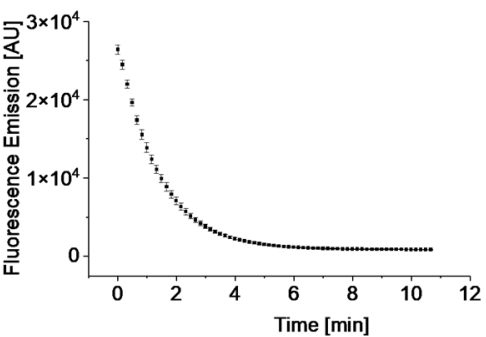

D

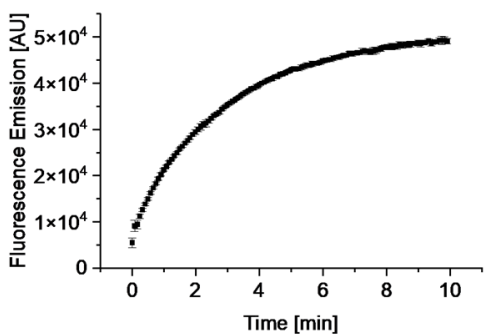

Figure 3. Photometric detection of $\beta$-glucosidase surrogate substrate hydrolysis in liquid assays. Shown are the resulting changes of signal intensity after the addition of almond $\beta$-glucosidase to a final concentration of $0.23 \mathrm{U} \mathrm{mL}^{-1}$ to $100 \mu \mathrm{L}$ of a $5 \mathrm{mM}$ glycoside solution ((A) arbutin, (B) esculin, (C) pNPG, (D) 4-MUG). Used wavelengths are given in the material and methods section. Experiments were conducted in triplicates. The values represent the mean values of three experiments and respective standard deviations.

\subsection{Assessment of Assay Limitations and Linearity}

Based on the previously performed experiments, 4-MUG and pNPG were identified as the most promising surrogate substrates. However, for the detailed characterization of $\beta$-glucosidases, a reliable quantification of the activity is of high importance. Due to the different measurement methods of the two surrogate substrates, differences in the quantification limits are very likely. To further investigate these differences, varying amounts of almond $\beta$-glucosidase were added to the surrogate substrates and the resulting signal increase was compared (Figure 4).

A

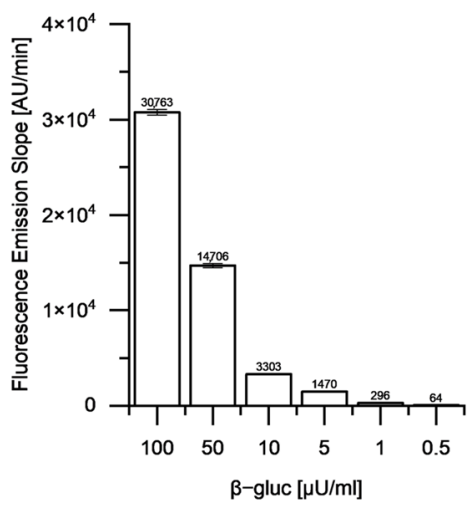

B

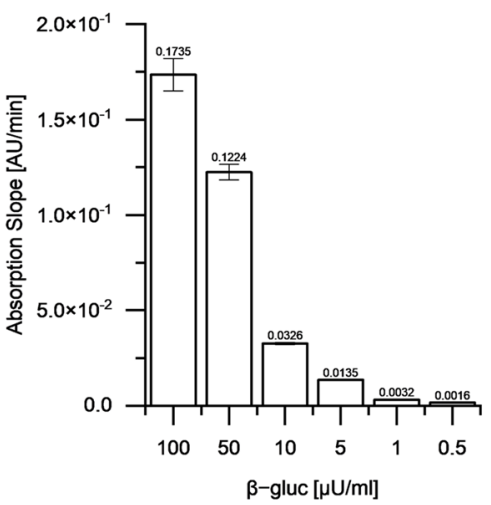

Figure 4. Comparison of enzyme activity quantification using 4-MUG or pNPG as surrogate substrates. The intensity increases of (A) 4-MU and (B) pNP signals after the addition of almond $\beta$-glucosidase to a final concentration of $100 \mu \mathrm{U} \mathrm{mL}^{-1}, 50 \mu \mathrm{UmL}^{-1}, 10 \mu \mathrm{U} \mathrm{mL}^{-1}, 5 \mu \mathrm{Um}^{-1}, 1 \mu \mathrm{U} \mathrm{mL}^{-1}$ and $0.5 \mu \mathrm{U} \mathrm{mL}^{-1}$ are illustrated. The signal emission slopes were calculated from measurements for $5 \mathrm{~min}$ after the addition of almond $\beta$-glucosidase. Experiments were conducted in triplicates. The values represent the mean values of three experiments and respective standard deviations. 
While a fluorescence signal intensity increase of 30,763 AU per minute could be detected with $100 \mu \mathrm{U} \mathrm{mL}^{-1}$ of the enzyme in the reaction with 4-MUG as substrate, the signal strength was reduced from $14,706 \mathrm{AU}$ per minute (50 $\mu \mathrm{U} \mathrm{mL}^{-1} \beta$-glucosidase), over $1470 \mathrm{AU}\left(5 \mu \mathrm{U} \mathrm{mL} \mathrm{m}^{-1} \beta\right.$-glucosidase) to $64 \mathrm{AU}\left(0.5 \mu \mathrm{U} \mathrm{mL}^{-1} \beta\right.$-glucosidase $)$. In comparison, the absorption increase resulting from pNP formation by equal amounts of almond $\beta$-glucosidase declined unequally especially with high enzyme concentrations. The absorption signal increase of 0.1735 AU per minute determined with $100 \mu \mathrm{U} \mathrm{mL}^{-1}$ of enzyme dropped to an absorption increase of $0.0016 \mathrm{AU}$ after the addition of $5 \mu \mathrm{U} \mathrm{ml}^{-1}$ of almond $\beta$-glucosidase.

Furthermore, the fluorescence signal increase of 4-MU is proportional to concentrations of almond $\beta$-glucosidase from $100 \mu \mathrm{U} \mathrm{mL}^{-1}$ to $1 \mu \mathrm{U} \mathrm{mL}{ }^{-1}$. Only the lowest tested enzyme amount $\left(0.5 \mu \mathrm{U} \mathrm{mL} \mathrm{m}^{-1}\right)$ was outside of the linear range. The observed changes in the absorption signal of pNP, in contrast, did only show a linear correlation for enzyme concentrations up to 10 or $50 \mu \mathrm{U} \mathrm{mL}^{-1}$. At least the value measured with $100 \mu \mathrm{UmL}^{-1}$ seems to be outside the linear range.

\subsection{Investigation of the $\mathrm{pH}$ Robustness of 4-MUG Assays}

Due to the strong $\mathrm{pH}$-dependence of $\mathrm{pNP}$ absorption [23], the samples have to be mixed with a $\mathrm{Na}_{2} \mathrm{CO}_{3}$ solution before the measurement. This procedure is time consuming, increases measurement inaccuracies and complicates kinetic measurements. To identify potential changes in the spectral properties of 4-MU, its emission spectra were analyzed at different $\mathrm{pH}$ levels (Figure 5A). Furthermore, the influence of different concentrations of glucose (Figure 5B) or ethanol (Figure 5C) was investigated.
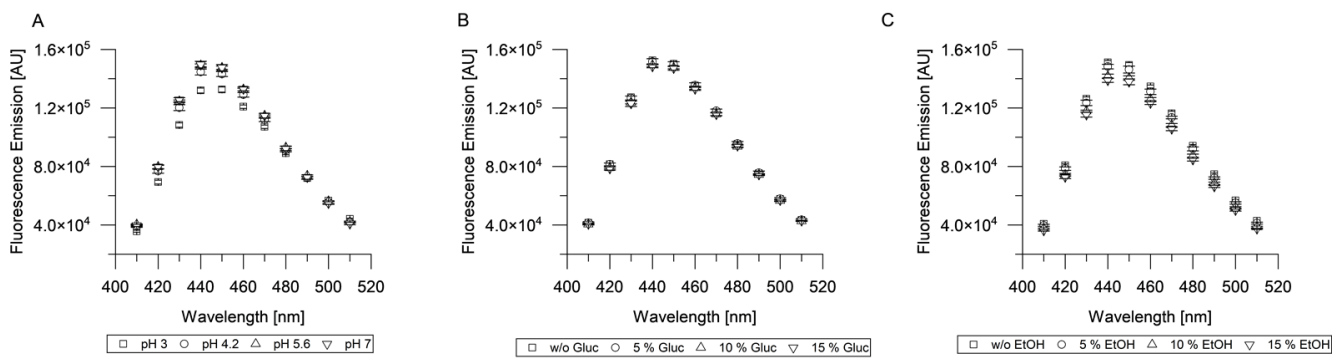

Figure 5. Investigation of 4-MU fluorescence variation due to changes of $\mathrm{pH}$ and ethanol or glucose addition. The absorption spectra illustrate the 4-MU emission spectra at (A) different $\mathrm{pH}$ values, (B) different concentrations of glucose or (C) different concentrations of ethanol. The excitation wavelength was $330 \mathrm{~nm}$. Experiments were conducted in triplicates. The values represent the mean values of three experiments and respective standard deviations. Whereas the addition of glucose did not affect the fluorescence emission, changes in the $\mathrm{pH}$ value or ethanol concentration resulted in slight changes of the signal intensity. With decreasing $\mathrm{pH}$ values, the fluorescence signal of 4-MUG was reduced from 150,000 units ( $\mathrm{pH} 7$ ) to 130,000 units ( $\mathrm{pH}$ 3). Moreover, the signal decreased from 150,000 units without the addition of ethanol to about 135,000 units at $15 \%$ v/v ethanol.

\subsection{Microscopic Investigation of 4-MU Localization in Cultures with $\beta$-Glucosidase Activity}

In order to test if 4-MUG can furthermore be used to investigate the localization of $\beta$-glucosidase enzymes in different strains, fluorescence microscopy analyses of cell cultures before and after the addition of 4-MUG (Figure 6) were performed. 

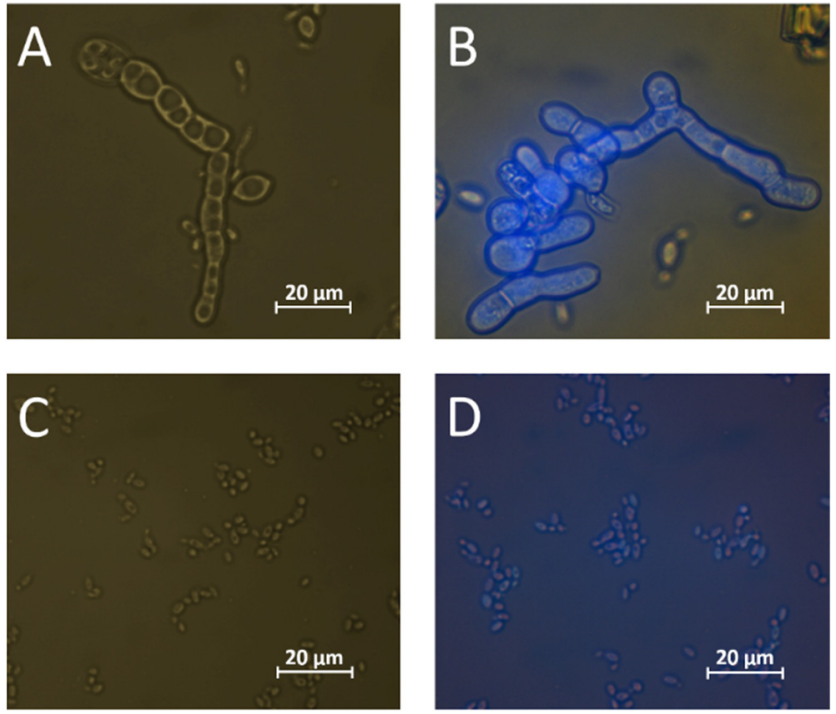

Figure 6. Visualization of 4-MU localization before (left) and after (right) the incubation of yeast cultures with 4-MUG. A. pullulans (A,B) and I. terricola (C,D) cultures were incubated with 4-MUG and analyzed via fluorescence microscopy as described in the material and methods section. The exposure time was identical for all pictures.

After addition of the surrogate substrate, A. pullulans cells clearly accumulated 4-MU in the cytoplasm (Figure 6B) which indicates a cytoplasmic localization of high amounts of the responsible $\beta$-glucosidase enzymes. In the case of I. terricola, 4-MU fluorescence could be detected in cells and in the culture medium (Figure 6D). This observation is consistent with the previously described secretion of significant amounts of $\beta$-glucosidase by this strain [9].

\section{Discussion}

In this comparative study of the most commonly used surrogate substrates, 4-MUG turned out to be most suitable for the photometric identification of $\beta$-glucosidase activities.

The described differences in solid and liquid assay conditions can be caused, for example, by the different availabilities of oxygen. Since the possible application of such strains takes place in a liquid environment (e.g., in a wine fermentation) and the liquid culture approach simplifies activity quantification, liquid assay conditions are most appropriate for screening.

Although arbutin and esculin were so far mainly used for the qualitative determination of $\beta$-glycosidic activities on agar plates, photometric determination and quantification is also possible under liquid assay conditions. Whereas the slow hydrolysis of arbutin is clearly a drawback for its potential use in a screening, esculin revealed to be suitable for this purpose. However, photometric detection of the substrate is more amenable to artifacts if compared to the detection of hydrolysis products in case of pNPG or 4-MUG.

A comparison of these two surrogate substrates revealed that the fluorescence-based assay is much more sensitive and apparently does not show saturation effects with the used enzyme concentrations. The possibility of adjusting the strength of the fluorescence signal amplification after the transformation from light into electricity (gain setting) in the case of more strongly deviating enzyme activities also leads to a considerable expansion of the measurable enzyme activities. In addition, the measurement of a fluorescent molecule is less influenced by cells and other sample ingredients compared to the absorption-based assay. Although pNPG has been commonly used as substrate for $\beta$-glucosidase characterization in previous studies [24-27], 4-MUG represents a highly suitable alternative surrogate substrate for screenings and kinetic investigations of $\beta$-glucosidase activities.

The detected changes in the spectral properties of 4-MU due to variation of $\mathrm{pH}$ or the addition of ethanol should be taken into account, but do not prevent the use of 
4-MUG as a surrogate substrate for $\beta$-glucosidase assays. To determine the amount of surrogate converted, separate calibration curves can be established for each tested condition. Therefore, 4-MUG assays were proven to be sufficiently robust against changes in the $\mathrm{pH}$ value and the addition of glucose or ethanol.

So far, 4-MUG has been frequently used in the context of Gaucher's disease $[17,28]$ to detect the lack of $\beta$-glucosidase activity in human cells $[29,30]$. Few reports exist about its use for the characterization of $\beta$-glucosidases in bacteria [31] and yeast [32] or for the staining of functional $\beta$-glucosidases in native polyacrylamide gels [33]. The use of 4-MUG for quantitative photometric $\beta$-glucosidase activity assays during a screening was reported by only two groups $[19,34]$.

Additional experiments suggest 4-MUG to be a useful probe for microscopic assessment of the potential enzyme localization. However, it should be noted, that direct conclusions concerning the subcellular localization of the enzymes are difficult to draw. It is also possible that the aglycon is transported into or out of the cells. However, 4-MUG might be useful for future investigations of subcellular $\beta$-glucosidase localization.

Supplementary Materials: The following supporting information can be downloaded at: https: / /www.mdpi.com/article/10.3390/fermentation8020083/s1, Figure S1: Fluorescence emission and absorption spectra of the investigated surrogate substrates. Fluores-cence was measured after excitation at the excitation maximum wavelength determined in the experiments. Experiments have been conducted in triplicates. (A) Arbutin, (B) Esculin, (C) pNPG, (D) 4-MUG.

Author Contributions: Conceptualization, F.M.R.G. and M.B.; methodology, F.M.R.G.; software, F.M.R.G.; validation, M.B.; formal analysis, M.B.; investigation, F.M.R.G.; resources, M.B.; data curation, M.B.; writing—original draft preparation, F.M.R.G.; writing—review and editing, M.B.; visualization, F.M.R.G.; supervision, M.B.; project administration, M.B.; funding acquisition, M.B. All authors have read and agreed to the published version of the manuscript.

Funding: This study was supported by the LOEWE project AROMAplus of the State of Hesse (Germany).

Institutional Review Board Statement: Not applicable.

Data Availability Statement: Not applicable.

Conflicts of Interest: The authors declare no conflict of interest. The funders had no role in the design of the study; in the collection, analyses, or interpretation of data; in the writing of the manuscript, or in the decision to publish the results.

\section{References}

1. Hjelmeland, A.K.; Ebeler, S.E. Glycosidically Bound Volatile Aroma Compounds in Grapes and Wine: A Review. Am. J. Enol. Vitic. 2015, 66, 1-11. [CrossRef]

2. Park, S.K.; Morrison, J.C.; Adams, D.O.; Noble, A.C. Distribution of free and glycosidically bound monoterpenes in the skin and mesocarp of Muscat of Alexandria grapes during development. J. Agric. Food Chem. 1991, 39, 514-518. [CrossRef]

3. Maicas, S.; Mateo, J.J. Hydrolysis of terpenyl glycosides in grape juice and other fruit juices: A review. Appl. Microbiol. Biotechnol. 2005, 67, 322-335. [CrossRef] [PubMed]

4. Bowles, D.; Lim, E.-K. Glycosyltransferases of Small Molecules: Their Roles in Plant Biology. eLS 2010. [CrossRef]

5. Schwab, W.; Fischer, T.; Wüst, M. Terpene glucoside production: Improved biocatalytic processes using glyco-syltransferases. Eng. Life Sci. 2015, 15, 376-386. [CrossRef]

6. Baffi, M.A.; Tobal, T.; Lago, J.H.G.; Boscolo, M.; Gomes, E.; Da-Silva, R. Wine aroma improvement using a $\beta$-glucosidase preparation from Aureobasidium pullulans. Appl. Biochem. Biotechnol. 2013, 169, 493-501. [CrossRef]

7. Bozoudi, D.; Tsaltas, D. The Multiple and Versatile Roles of Aureobasidium pullulans in the Vitivinicultural Sector. Fermentation 2018, 4, 85. [CrossRef]

8. Saha, B.C.; Freer, S.N.; Bothast, R.J. Production, Purification, and Properties of a Thermostable $\beta$-Glucosidase from a Color Variant Strain of Aureobasidium pullulans. Appl. Environ. Microbiol. 1994, 60, 3774-3780. [CrossRef]

9. González-Pombo, P.; Fariña, L.; Carrau, F.; Batista-Viera, F.; Brena, B.M. A novel extracellular beta-glucosidase from Issatchenkia terricola: Isolation, immobilization and application for aroma enhancement of white Muscat wine. Process. Biochem. 2011, 46, 385-389. [CrossRef]

10. Ariaeenejad, S.; Nooshi-Nedamani, S.; Rahban, M.; Kavousi, K.; Pirbalooti, A.G.; Mirghaderi, S.; Mohammadi, M.; Mirzaei, M.; Salekdeh, G.H. A Novel High Glucose-Tolerant $\beta$-Glucosidase: Targeted Computational Ap-proach for Metagenomic Screening. Front. Bioeng. Biotechnol. 2020, 8, 813. [CrossRef] 
11. Zang, X.; Liu, M.; Fan, Y.; Xu, J.; Xu, X.; Li, H. The structural and functional contributions of $\beta$-glucosidase-producing microbial communities to cellulose degradation in composting. Biotechnol. Biofuels 2018, 11, 51. [CrossRef] [PubMed]

12. Aizawa, K. Studien über Carbohydrase: Die fermentative Hydrolyse der p-Nitrophenol-glukoside. J. Biochem. 1939, 30, 89-100. [CrossRef]

13. Rosi, I.; Vinella, M.; Domizio, P. Characterization of beta-glucosidase activity in yeasts of oenological origin. J. Appl. Bacteriol. 1994, 77, 519-527. [CrossRef] [PubMed]

14. Miskin, A.; Edberg, S.C. Esculin hydrolysis reaction by Escherichia coli. J. Clin. Microbiol. 1978, 7, 251-254. [CrossRef]

15. Pérez, G.; Fariña, L.; Barquet, M.; Boido, E.; Gaggero, C.; Dellacassa, E.; Carrau, F. A quick screening method to identify $\beta$-glucosidase activity in native wine yeast strains: Application of Esculin Glycerol Agar (EGA) medium. World J. Microbiol. Biotechnol. 2011, 27, 47-55. [CrossRef]

16. Oftedal, L.; Maple-Grødem, J.; Førland, M.G.G.; Alves, G.; Lange, J. Validation and assessment of preanalytical factors of a fluorometric in vitro assay for glucocerebrosidase activity in human cerebrospinal fluid. Sci. Rep. 2020, 10, 22098. [CrossRef] [PubMed]

17. Peters, S.P.; Lee, R.E.; Glew, R.H. A microassay for Gaucher's disease. Clin. Chim. Acta 1975, 60, 391-396. [CrossRef]

18. Charoenchai, C.; Fleet, G.H.; Henschke, P.A.; Todd, B.E.N. Screening of non-Saccharomyces wine yeasts for the presence of extracellular hydrolytic enzymes. Aust. J. Grape Wine Res. 1997, 3, 2-8. [CrossRef]

19. Fia, G.; Giovani, G.; Rosi, I. Study of beta-glucosidase production by wine-related yeasts during alcoholic fer-mentation. A new rapid fluorimetric method to determine enzymatic activity. J. Appl. Microbiol. 2005, 99, 509-517. [CrossRef]

20. Mendes Ferreira, A.; Clímaco, M.C.; Mendes Faia, A. The role of non-Saccharomyces species in releasing glyco-sidic bound fraction of grape aroma components-A preliminary study. J. Appl. Microbiol. 2001, 91, 67-71. [CrossRef]

21. Sapkota, A. Available online: https://microbenotes.com/bile-esculin-test/ (accessed on 16 September 2021).

22. Liu, J.; Bao, H.; Liu, C.; Wu, F.; Gao, F. “Turn-On” Fluorescence Determination of $\beta$-Glucosidase Activity Using Fluorescent Polymer Nanoparticles Formed from Polyethylenimine Cross-Linked with Hydroquinone. Appl. Polym. Mater. 2019, 1, $3057-3063$. [CrossRef]

23. Bowers, G.N.; McComb, R.B.; Christensen, R.G.; Schaffer, R. High-Purity 4-Nitrophenol: Purification, Charac-terization, and Specifications for Use as a Spectrophotometric Reference Material. Clin. Chem. 1980, 26, 724-729. [CrossRef]

24. Karnchanatat, A.; Petsom, A.; Sangvanich, P.; Piaphukiew, J.; Whalley, A.J.S.; Reynolds, C.D.; Sihanonth, P. Purification and biochemical characterization of an extracellular beta-glucosidase from the wood-decaying fungus Daldinia eschscholzii (Ehrenb.:Fr.) Rehm. FEMS Microbiol. Lett. 2007, 270, 162-170. [CrossRef]

25. Larue, K.; Melgar, M.; Martin, V.J.J. Directed evolution of a fungal $\beta$-glucosidase in Saccharomyces cerevisiae. Biotechnol. Biofuels 2016, 9, 52. [CrossRef]

26. Schmidt, S.; Rainieri, S.; Witte, S.; Matern, U.; Martens, S. Identification of a Saccharomyces cerevisiae gluco-sidase that hydrolyzes flavonoid glucosides. Appl. Environ. Microbiol. 2011, 77, 1751-1757. [CrossRef]

27. Kuo, H.-P.; Wang, R.; Huang, C.-Y.; Lai, J.-T.; Lo, Y.-C.; Huang, S.-T. Characterization of an extracellular $\beta$-glucosidase from Dekkera bruxellensis for resveratrol production. J. Food. Drug. Anal. 2018, 26, 163-171. [CrossRef] [PubMed]

28. van Smeden, J.; Dijkhoff, I.M.; Helder, R.W.J.; Al-Khakany, H.; Boer, D.E.C.; Schreuder, A.; Kallemeijn, W.W.; Absalah, S.; Overkleeft, H.S.; Aerts, J.M.F.G.; et al. In situ visualization of glucocerebrosidase in human skin tissue: Zymography versus activity-based probe labeling. J. Lipid Res. 2017, 58, 2299-2309. [CrossRef] [PubMed]

29. Takahashi, T.; Nishio, H.; Kodama, S.; Nakamura, H. $\beta$-Glucosidase activity in liver, spleen and brain in acute neuropathic gaucher disease. Brain Dev. 1990, 12, 202-205. [CrossRef]

30. Fleury, D.; Domaingue, P.; Gillard, C.; Touitou, R.; Mollat, P. Expression, purification, characterization and crystallization of a recombinant human cytosolic beta-glucosidase produced in insect cells. Protein Expr. Purif. 2007, 52, 96-103. [CrossRef]

31. Setlow, B.; Cabrera-Hernandez, A.; Cabrera-Martinez, R.M.; Setlow, P. Identification of ar-yl-phospho-beta-D-glucosidases in Bacillus subtilis. Arch. Microbiol. 2004, 181, 60-67. [CrossRef]

32. Turan, Y.; Zheng, M. Purification and characterization of an intracellular beta-glucosidase from the methylotrophic yeast Pichia pastoris. Biochemistry 2005, 70, 1363-1368. [CrossRef] [PubMed]

33. Michlmayr, H.; Schümann, C.; Barreira Braz Da Silva, N.M.; Kulbe, K.D.; Del Hierro, A.M. Isolation and basic characterization of a beta-glucosidase from a strain of Lactobacillus brevis isolated from a malolactic starter culture. J. Appl. Microbiol. 2010, 108, 550-559. [CrossRef] [PubMed]

34. Bell, C.W.; Fricks, B.E.; Rocca, J.D.; Steinweg, J.M.; McMahon, S.K.; Wallenstein, M.D. High-throughput fluo-rometric measurement of potential soil extracellular enzyme activities. JoVE (J. Vis. Exp.) 2013, 81, e50961. [CrossRef] 